\title{
On the Utility Consistency of Poverty Lines
}

\author{
Martin Ravallion and Michael Lokshin ${ }^{1}$ \\ Development Research Group, World Bank, \\ 1818 H Street NW, Washington DC, USA
}

\begin{abstract}
Although poverty lines are widely used as deflators for inter-group welfare comparisons, their internal consistency is rarely given close scrutiny. $A$ priori considerations suggest that commonly used methods cannot be relied upon to yield poverty lines that are consistent in terms of utility, or for capabilities more generally. The theory of revealed preference offers testable implications of utility consistency for "poverty baskets" under given preferences. A case study of Russia's official poverty lines reveals numerous violations of revealed preference criteria - violations that are not solely attributable to heterogeneity in preferences associated with climatic differences.
\end{abstract}

JEL: D12, I32, R13

Keywords: Poverty lines, revealed preference, capabilities, nutrition, Russia

World Bank Policy Research Working Paper 3157, October 2003

The Policy Research Working Paper Series disseminates the findings of work in progress to encourage the exchange of ideas about development issues. An objective of the series is to get the findings out quickly, even if the presentations are less than fully polished. The papers carry the names of the authors and should be cited accordingly. The findings, interpretations, and conclusions expressed in this paper are entirely those of the authors. They do not necessarily represent the view of the World Bank, its Executive Directors, or the countries they represent. Policy Research Working Papers are available online at http://econ.worldbank.org.

$1 \quad$ For comments the authors are grateful to Stefan Klonner and participants at the 2003 Cornell University Conference of "Poverty, Inequality and Development" in honor of Erik Thorbecke. These are the views of the authors, and need not reflect those of the World Bank or any affiliated organization. Correspondence: mravallion@worldbank.org, mlokshin@worldbank.org. 


\section{Introduction}

Poverty profiles - showing how a measure of poverty varies across sub-groups of a population - are widely used to inform policies for fighting poverty. A key ingredient is a set of poverty lines, to be used as deflators applied to sub-group specific distributions of income. Various methods are found in practice for setting poverty lines and the methodological choices made can matter greatly to the policy implications drawn. For example, a case study for Indonesia found virtually zero rank correlation between the regional poverty measures implied by two common methods of setting poverty lines (Ravallion and Bidani, 1994). This suggests that it is important to probe critically into the methods used to set poverty lines in practice. In identifying principles for choosing between alternative methods, the most obvious criterion for an economist is utility consistency, meaning that the poverty line for each sub-group is the cost of a common (inter-personally comparable) utility level across all sub-groups.

This paper explores the implications of utility consistency for applied work. Poverty lines are usually anchored to nutritional requirements for good health and normal activities. But there are many ways this can be done. There are two common methods of setting poverty lines in practice: the "Food-Energy Intake" (FEI) method and the "Cost-of-Basic Needs" (CBN) method. $^{2}$ The FEI method finds the income or expenditure level at which pre-determined foodenergy requirements are met in expectation within each sub-group. There is no explicit bundle of goods in the FEI method. The CBN method, by contrast, sets specific poverty bundles and costs them in each sub-group. The food bundles are typically anchored to nutritional

\footnotetext{
2 For an overview of alternative methods found in practice see Ravallion (1998). Note that we refer here to commonly used "objective" poverty lines. Subjective poverty lines can also be defined and measured and we believe that this approach has a number of attractions, as discussed in (inter alia) Kapteyn et al., (1988) and Pradhan and Ravallion (2000).
} 
requirements given prevailing diets, but allowances for non-food goods and services are also included.

The paper argues that FEI poverty lines are unlikely to be utility consistent. CBN poverty lines are potentially utility consistent, but whether they are in practice is unclear. We explore one way of assessing the utility consistency of CBN poverty lines, based on longstanding ideas on the use of quantity indices in comparing alternative price and quantity combinations, invoking Samuelson's (1938) theory of revealed preference. ${ }^{3}$ This yields testable necessary conditions for utility consistency for given preferences over commodities.

As a case study, we apply these ideas to an assessment of Russia's official poverty lines, which use an elaborate version of the $\mathrm{CBN}$ method. Russia's striking climatic differences across regions mean that the same consumption bundle is unlikely to yield the same utility. (Large regions of Russia have average annual temperatures well below freezing, while other regions have moderate northern-European climates.) By implication, CBN poverty lines should have higher value (assessed by a quantity index) in colder climates. That is what we find in the data. However, we also find differences within similar climatic regions, and numerous violations of revealed preference criteria.

Section 2 discusses alternative theoretical foundations for defining the consistency of poverty lines. Section 3 then focuses on FEI poverty lines. Section 4 turns to CBN poverty lines, while section 5 develops our revealed-preference tests for their utility consistency. We then carry the results of section 5 to our assessment of Russia's official poverty lines; section 6 describes our data, while section 7 presents our results. Conclusions can be found in section 8 .

\footnotetext{
3 For excellent overviews of the theory see Sen (1979) and Deaton and Muellbauer (1980, section 2.6 on revealed preference theory; also see section 7.2 on quantity indices).
} 


\section{Consistency of poverty lines in theory}

A poverty line can be defined as the money needed to achieve the minimum level of "well-being" that is required to not be deemed "poor." Thus everyone at the poverty line (no matter what sub-group they happen to belong) is deemed to be equally badly off, and all those below the line are worse off than all those above it. This much can be easily agreed. The more difficult question is what concept of well-being should serve as the anchor for poverty lines? For economists the obvious answer is "utility." A justification for utility consistent poverty lines can be found by applying standard welfare-economic principles to poverty measurement. These principles are that assessments of social welfare (including poverty measures) should depend solely on utilities, people with the same initial utility should be treated the same way, and social welfare should not be decreasing in any utility.

To formalize this approach to setting poverty lines, consider household $i$ in sub-group $j$ with characteristics $x_{i j}$ (a vector). ${ }^{4}$ The household's preferences are represented by an interpersonally comparable utility function $u_{j}\left(q_{i j}, x_{i j}\right)$. The household chooses its consumption vector $q_{i j}$ to maximize utility. Notice that we allow the possibility that the same commodity bundle can yield different utility levels in different subgroups for households with the same characteristics. For example, a given bundle may yield a higher utility in a warm climate than a cold one, where more will be needed for clothing and energy.

The utility-consistent poverty line is the point on the consumer's expenditure function corresponding to a common reference utility level and prevailing prices. The consumer's expenditure function is $e_{j}\left(p_{i j}, x_{i j}, u\right)$, giving the minimum cost of utility $u$ in sub-group $j$ when

\footnotetext{
$4 \quad$ Ideally this would be the characteristics of individual rather than households. That is an important distinction, but not one that is implementable with the data normally available for measuring poverty.
} 
facing the price vector $p_{i j}$ with household characteristics $x_{i j}$. Let $u_{z}$ denote the minimum utility level deemed to be needed to escape poverty; consistency requires that this is a constant. The money metric of $u_{z}$ defines a set of utility-consistent poverty lines:

$$
z_{i j}^{u}=e_{j}\left(p_{i j}, x_{i j}, u_{z}\right) \text { for all }(i, j)
$$

When expenditure is deflated by such a poverty line one obtains a welfare metric with a number of desirable theoretical properties for policy analysis (Blackorby and Donaldson, 1987). ${ }^{5}$

For economists, utility is the obvious anchor for setting poverty lines. However, it is not the only possible approach, and nor is it the approach that has had most influence on practices in applied work on poverty (as we will show in the following sections). Capability-based concepts of well-being offer an alternative theoretical foundation for poverty measurement. Indeed, this can be viewed as an encompassing framework, for which utility consistency is a special case.

While versions of this approach go back a long way in philosophy and the social sciences, it can be characterized today in the terms of Amartya Sen's argument that "well-being" should be thought of in terms of a person's capabilities, i.e., the functionings ("beings and doings") that a person is able to achieve (Sen, 1985). By this view, poverty means not having an income sufficient to support specific normative functionings. Utility — as the attainment of personal satisfaction — can be viewed as one such functioning relevant to well-being (Sen, 1992, Chapter 3). But it is only one of the functionings that matter. Independently of utility, one might say that a person is better off if she is able to participate fully in social and economic activity, for example. Notice that poverty is not defined by actual achievement of these functionings, but rather by the capability of achieving them.

\footnotetext{
$5 \quad$ Such poverty lines can also be used to construct true cost-of-living indices, by normalizing the poverty line by its value for some reference group (see, for example, Deaton and Muellbauer, 1980).
} 
To formalize this approach, let a household's functionings be determined by the goods it consumes and its characteristics. The vector of actual functionings for household $i$ in group $j$ is:

$$
f_{i j}=f_{j}\left(q_{i j}, x_{i j}\right)
$$

where $f$ is a vector-valued function. The quantities consumed are assumed to be utility maximizing, giving demand functions $q_{i j}=q_{j}\left(p_{i j}, y_{i j}, x_{i j}\right)$ at total expenditure $y_{i j}$. One can also postulate that the household has preferences over functionings, for which $u_{j}\left(q_{i j}, x_{i j}\right)$ is then a derived utility function, obtained by substituting (2) into the (primal) utility function defined over functionings (Ravallion, 1998).

Capability-consistency requires that certain normative funtionings are reached at the poverty line in each sub-group. Let $f_{z}$ denote the vector of critical functionings deemed to be needed to be not poor. (These are normative judgments, just as $u_{z}$ is a normative judgment.) A commodity bundle, $q_{i j}^{c}$, is identified such that no functioning is below its critical value:

$$
f_{z} \leq f_{j}\left(q_{i j}^{c}, x_{i}\right)
$$

There could well be more than one solution for $q_{i j}^{c}$ satisfying (3). Each solution yields a set of capability-consistent poverty lines $z_{i j}^{c}=p_{i j} q_{i j}^{c}$ when $q_{i j}^{c}$ is valued at local prices. Two ways can be suggested for choosing a single capability-consistent poverty line for each subgroup. The first possible way to resolve the indeterminacy of multiple solutions is to pick the bundle that minimizes the expenditure $p_{i j} q_{i j}^{c}$ over the set of all $q_{i j}^{c}$ satisfying (3). Or one can define $z_{i j}^{c}$ as the minimum $y$ such that:

$$
f_{z} \leq f_{j}\left[q_{j}\left(p_{i j}, y, x_{i j}\right), x_{i j}\right]
$$


Notice that one or more specific functionings will be decisive in determining $z_{i j}^{c}$, namely the functioning that is the last to reach its critical value as income rises. In this sense, the lowest priority functioning for the household given its preferences over functionings will be decisive.

A second possible approach is to treat attainments as a random variable (i.e., with a probability distribution) and take a mean conditional on income and other identified covariates, including group membership. Then poverty lines are deemed to be capability consistent if $f_{z}$ is reached in expectation. This second approach is closer to current practices for an important class of methods for setting poverty lines, which we turn to in the next section.

\section{The food-energy-intake method}

The FEI method can be interpreted as a special case of the capability-based approach described above. The specialization is to focus on just one functioning, namely food-energy intake. The method finds the consumption expenditure or income level at which food energy intake is just sufficient to meet pre-determined food energy requirements for good health and normal activity levels. (Such caloric requirements are given in WHO, 1985, for example.) To deal with the fact that food energy intakes naturally vary at a given income level, the FEI method typically calculates an expected value of intake at given income. Figure 1 illustrates the method. The vertical axis is food-energy intake, plotted against income (or expenditure) on the horizontal axis. A line of "best fit" is indicated; this is the expected value of caloric intake at given income (i.e., the nonlinear regression function). By simply inverting this line, one finds the income $z$ at which a person typically attains the stipulated food-energy requirement. ${ }^{6}$ This method, or

\footnotetext{
$6 \quad$ Some versions of the FEI method regress (or graph) nutritional intake against consumption expenditure and invert the estimated function, while others avoid this step by simply regressing
} 
something similar, has been used often, including by Dandekar and Rath (1971), Osmani (1982), Greer and Thorbecke (1986), Paul (1989), Palmer-Jones and Sen (2001), and by numerous governmental statistics offices. It is probably the most common method found in practice in developing countries.

To explain the method more formally, let $k$ denote food-energy intake, which is taken to be a random variable. The stipulated requirement level is $k^{r}$ which is taken to be fixed for given characteristics, such as age. As long as the expected value of food-energy intake conditional on total consumption expenditure, $E(k \mid y)$, is strictly increasing in $y$ over an interval that includes $k^{r}$ there will exist a FEI poverty line, $z^{F E I}$, defined implicitly by:

$$
E\left(k \mid z^{F E I}\right)=k^{r}
$$

Three points are notable. Firstly, the method is aiming to measure income poverty, rather than undernutrition. If one wanted to measure undernutrition, one would simply look at how many people had nutritional intakes $k \leq k^{r}$, ignoring incomes or consumption expenditures.

Secondly, the method is computationally simple. A common practice is to calculate the mean income or expenditure of a sub-sample of households whose estimated caloric intakes are approximately equal to the stipulated requirements. More sophisticated versions use regressions of the empirical relationship between food energy intakes and consumption expenditure. These can be readily used (numerically or explicitly) to calculate the FEI poverty line. The method avoids the need for price data; in fact, no explicit valuations are required.

Thirdly, the method automatically includes non-food consumption as long as one locates the total consumption expenditure at which a person typically attains the caloric requirement. though the difference is not germane to our present interest; either way the following points apply. 
Can the FEI method assure that the resulting poverty lines will be consistent in terms of utility or capabilities more generally? To assess their utility consistency, consider first how FEI poverty lines respond to differences in relative prices, which can of course differ across the subgroups (such as regions) being compared in the poverty profile and over time. For example, the prices of many non-food goods are likely to be lower relative to foods in urban than in rural areas. This will probably mean that the demand for food and (hence) food energy intake will be lower in urban than in rural areas, at any given real income. But this does not, of course, mean that urban households are poorer at a given expenditure level.

To see the problem more clearly, let there be two composite goods, "food" and "nonfood" consumed in quantities $q_{0}$ and $q_{1}$ respectively, and let $p$ denote the relative price of the non-food good. The utility-consistent poverty line is (simplifying notation) $z^{u}=e\left(p, u_{z}\right)$. By the envelope property, the derivative of $z$ w.r.t $p$ is simply the level of consumption of non-food goods for someone at the poverty line. As long as both goods are consumed, a higher relative price of non-food goods must mean a higher poverty line in terms of food.

However, this no longer holds using the FEI method to set the poverty line. Then one fixes instead the value of $q_{0}$ at the (unique) level needed to achieve the stipulated food-energy level. The corresponding FEI poverty line is $z^{F E I}$ such that $q_{0}\left(p, z^{F E I}\right)$ is the required food consumption, where $q_{0}(p, y)$ denotes the food demand function. The derivative of the FEI poverty line w.r.t. the price of non-food goods is now:

$$
\frac{\partial z^{F E I}}{\partial p}=-\frac{q_{0 p}\left(p, z^{F E I}\right)}{q_{0 y}\left(p, z^{F E I}\right)}
$$


where the subscripts " $p$ " and " $y$ " denote the partial derivatives w.r.t. those variables. It is reasonable to assume that non-food goods are normal $\left(q_{0 y}>0\right)$. The sign of (6) will then depend on whether food and non-food goods are (uncompensated) substitutes $\left(q_{0 p}>0\right)$ or complements $\left(q_{0 p}<0\right)$. In the former case, the FEI poverty line will decrease with an increase in the price of non-food goods. A lower relative price of non-food goods in urban areas, for example, will perversely yield a higher poverty line using this method. The FEI poverty lines will then fail our consistency requirement since the consistent poverty lines must be increasing in all prices, given that this must hold for the consumer's expenditure function. Utility consistency would requite that food and non-food goods are complements.

There are other reasons to question the utility consistency of FEI poverty lines. Even if relative prices do not differ, the relationship between food energy intake and income will shift according to differences in tastes, activity levels and publicly-provided goods. There is nothing in the FEI method to guarantee that these differences are ones that would normally be considered relevant to assessing welfare. For example, tastes can differ across sub-groups even if relative prices do not. At given relative prices and real total expenditure, urban households may simply have more expensive food tastes than rural households; they eat more animal protein and less calories from starchy food staples, or simply eat out more often. Thus they pay more for each calorie, or (equivalently) food energy intake will be lower at any given real expenditure level. It is unclear why we would deem a person who chooses to buy fewer and more expensive calories as poorer than another person at the same real expenditure level. For these reasons, the real income at which an urban resident typically attains any given caloric requirement will tend to be higher than in rural areas. And this can hold even if the cost of living is no different between urban and rural areas. 
Consider Figure 2, which gives a stylized food energy-income relationship for "urban" and "rural" areas. The urban poverty line is $z_{u}$ while the rural line is $z_{r}$. However, the aforementioned concerns lead us to question whether the differential $z_{u} / z_{r}$ could provide any reasonable approximation to the true differential in the cost of the same standard of living. The distribution of caloric intakes can readily vary between groups such that the regression function $E(k \mid y)$ also varies with the characteristics of those groups, and there is no reason to assume that $E(k \mid y)$ ranks welfare levels correctly at a given value of $y$. A differential in poverty lines can then appear, making the poverty profile utility inconsistent.

It is clear from these observations that one should then be wary of poverty lines generated by the FEI method if the aim is to reduce utility poverty; people at the poverty line in different sub-groups could well have very different levels of welfare defined as utility. Indeed, it is quite possible to find that the "richer" sector (by the agreed metric of utility) tends to spend so much more on each calorie that it is deemed to be the "poorer" sector. That has been found to be the case in studies of the properties of FEI poverty profiles for Indonesia (Ravallion and Bidani, 1994) and Bangladesh (Ravallion and Sen, 1996; Wodon, 1997).

Problems also arise in comparisons over time. Suppose that all prices increase, so the cost of a given utility must rise. There is nothing to guarantee that the FEI-based poverty line will increase. That will depend on how relative prices and tastes change; the price changes may well encourage people to consume cheaper calories, and so the FEI poverty line will fall. Wodon (1997) gives an example of this problem in data for Bangladesh. The FEI poverty line fell over time even though prices generally increased.

The potential utility inconsistencies in FEI poverty lines are worrying when there is mobility across the subgroups of the poverty profile, such as due to inter-regional migration. 
Suppose that. as the above discussion has suggested may well happen. the FEI poverty line has higher purchasing power in urban areas than rural areas. Consider someone just above the FEI poverty line in the rural sector who moves to the urban sector and obtains a job there generating a real gain less than the difference in poverty lines across the two sectors. Though that person is better off. in that she can buy more of all goods, including food. the aggregate measure of poverty across the sectors will show an increase, as the migrant will now be deemed poor in the urban sector. Indeed, it is possible that a process of economic development through urban sector enlargement, in which none of the poor are any worse off, and at least some are better off, would result in a measured increase in poverty.

What about the capability consistency of FEI poverty lines? By construction, the FEI lines are consistent with respect to one important functioning, namely reaching nutritional requirements. The issue is whether that constitutes a good basis for poverty comparisons. It might be if one deemed food-energy intake to be the sole capability of interest. But there appears to be wide agreement that it is not, even among exponents of the FEI method. For if one deemed calories to be sufficient, none of this extra work would be necessary - all one would do is measure caloric shortfalls relative to requirements (all of which are already needed as data to implement this method of setting poverty lines). The FEI method acknowledges (at least implicitly) that meeting food-energy requirements is not enough.

To believe that FEI poverty lines are consistent for some broader set of functionings we must assume that meeting nutritional requirements has a low priority for people, for only then can we be sure that all other functionings have been reached once nutritional requirements have been reached. That is surely implausible on a priori grounds; if anything one would expect that food energy requirements had a relatively high priority. 
In summary, a FEI-based poverty profile will not in general be utility consistent. Nor is capability consistency likely to hold over a broader set of functionings. Next we turn to the main alternative method found in practice.

\section{The cost-of-basic-needs method}

The CBN method stipulates a consumption bundle deemed to be adequate for "basic consumption needs," and then estimates its cost for each of the subgroups being compared in the poverty profile. This is the approach of Rowntree in his seminal study of poverty in York, England, in 1899, and there have been numerous examples since, including the official poverty lines for the U.S. ${ }^{7}$ Some form of capability consistency is assured by construction, since various valued functionings are essentially the starting point for defining "basic consumption needs." The poverty bundle is typically anchored to food-energy requirements consistently with common diets in the specific context. However, allowances for non-food goods are also included, to assure that basic non-nutritional functionings are assured. We give an example of how CBN poverty lines are constructed in section 6 , when we discuss Russia's poverty lines.

Superficially, the CBN method looks like a more promising route to utility-consistent poverty lines. The CBN poverty line can be written as the expenditure needed to achieve a specific bundle of goods. Similarly, the "ideal" utility-consistent poverty line in equation (1) can be written:

$$
z_{i j}^{u}=p_{i j} q_{j}\left(p_{i j}, x_{i j}, u_{z}\right)
$$

The CBN method will be utility consistent if the right bundle is used, corresponding to the relevant points on the utility-compensated (Hicksian) demand functions.

\footnotetext{
$7 \quad$ See Orshansky (1965) and Citro and Michael (1995).
} 
However, there is nothing to guarantee that the bundles of goods built into CBN poverty lines lie on the compensated demand functions, at the (common) reference level of utility (as in equation 7). Thus it is important to have some way of assessing a set of CBN poverty bundles. We explore one approach below, drawing in the theory of revealed preference.

A common problem in setting $\mathrm{CBN}$ poverty lines is missing data on non-food prices. A number of solutions have been proposed (as reviewed in Ravallion, 1998). The most common practice is to divide the food component by an estimate of the budget share devoted to food. For example, the widely used poverty line for the U.S. developed by Orshansky (1963) assumes a food share of one third, which was the average food share in the U.S. at the time. The total poverty line was set at three times the food poverty line.

However, the basis for choosing a food share is rarely transparent, and very different poverty lines can result, depending on the choice made. Why use the average food share, as in the Orshansky line? Whose food share should be used? Arguably a more appealing approach is to set an allowance for non-food goods that is consistent with demand behavior at (or in a region of) the food poverty line as proposed in Ravallion (1994). This will not be an issue in our empirical application (for which a complete set of goods is specified), but it may generate further concerns about consistency in other applications.

\section{Assessing CBN poverty lines by revealed preference}

In practice, the most common application is likely to be the geographic poverty profile, so this is the case we focus on in the following exposition. Each geographic area (which could 
be a country) has its own poverty line, which is the cost in that area of a bundle of goods specific to that area. ${ }^{8}$

It is convenient to change notation slightly such that $q_{i}=\left(q_{i}^{1}, \ldots, q_{i}^{m}\right)$ is the $m$-vector giving the CBN poverty bundle for region $i=1, . . n$. (The bundle can also vary with household characteristics, but we ignore this to simplify notation.) The corresponding price vector is $p_{i}$ and the poverty line in region $i$ is $z_{i}=p_{i} q_{i}$. Let $r_{i}=\left(p_{i}^{1} / z_{i}, \ldots, p_{i}^{m} / z_{i}\right)$ denote the vector of price relatives for region $i$, normalized by the poverty line, and let $\boldsymbol{P} \equiv\left\{r_{i}, i=1, \ldots, n\right\}$ denote the set of all price relatives.

We define the $n \times n$ quantity-index matrix $\boldsymbol{Q}$ for which the $i$ 'th row and $j^{\prime}$ th column give the cost of $j$ 's poverty bundle when valued at $i$ 's price relatives:

$$
Q_{i j} \equiv r_{i} q_{j}=\frac{p_{i} q_{j}}{p_{i} q_{i}}
$$

For example, in the case of $n=2$, the matrix is:

$$
\boldsymbol{Q}=\left[\begin{array}{cc}
1 & r_{1} q_{2} \\
r_{2} q_{1} & 1
\end{array}\right]
$$

We use the $\boldsymbol{Q}$ matrix to compare poverty bundles across regions; the higher $Q_{i j}$ the higher the value of the poverty bundle for region $j$ when judged by its cost in region $i$. The quantity index ranks poverty bundles across regions conditional on the price relatives.

We will say that the bundle for region $k$ is "unconditionally higher" than the bundle for region $j$ if $Q_{i k} \geq Q_{i j}$ for all $r_{i}$ in $\boldsymbol{P}$. This means that all elements of the $j^{\prime}$ th column of $\boldsymbol{Q}$ are

\footnotetext{
$8 \quad$ For example, one way of setting the different bundles of goods is to base them on the actual consumption pattern in each region of a reference segment of the national population that is initially taken to be poor. Following the method described in Ravallion (1998) one can iterate until there is convergence such that the reference segment is in fact deemed to be in a neighborhood of the poverty line.
} 
greater than the corresponding elements of the $k^{\prime}$ th column. There is no guarantee that such a ranking is possible; that is an empirical question.

To provide a summary statistic for the value of each region's poverty line we can calculate the simple mean quantity index formed by taking the column totals of the $\boldsymbol{Q}$ matrix; we write this index as $\bar{Q}_{j}=\sum_{i=1}^{n} Q_{i j} / n$. Finding that $\bar{Q}_{j}>\bar{Q}_{k}$ implies that bundle $j$ dominates $k$ at least partially (for some price relatives in $\boldsymbol{P}$ ), though (of course) not necessarily fully.

Can we decide whether a set of CBN poverty lines are utility consistent based on revealed preference theory? Consider, two regions, A and B, each of which has a poverty line, which is the cost in each region of pre-specified bundles of goods specific to each region. Our definition of consistency requires that these two bundles yield the same utility and are both utility-maximizing in their respective regions for someone at the poverty line.

If preferences are identical in the two regions, then there is a straightforward revealed preference test. This requires that the poverty line for $\mathrm{A}$ is no greater than the cost in region $\mathrm{A}$ of B's bundle, for otherwise the bundle in B is affordable when A was chosen, implying that A is preferred. Similarly, the region B poverty line cannot be greater than the cost in that region of the bundle for A. If this test fails than we can reject consistency for a broad class of possible preferences, though passing the test does not assure consistency for all possible preferences.

To outline the revealed preference test in more formal terms, assume that the (unknown) preferences over commodities of those living in region $i$ can be represented by a utility function $u_{i}($.$) . (To simplify notation we treat households as homogeneous in all respects except their$ income and location, so we can drop the " $x$ " for non-income characteristics from all functions, but allowing the function itself to vary by location.) Preferences are allowed to vary regionally due to (inter alia) differences in climate or differences in endowments of local public goods. We 
make the standard assumption that $u_{i}($.$) traces out strictly convex indifference curves (though$ this can be weakened somewhat).

Consistency of $\mathrm{CBN}$ poverty lines relative to the preferences in region $i$ requires that:

$$
\begin{aligned}
& z_{i}=e_{i}\left(p_{i}, u_{z}\right) \\
& u_{i}\left(q_{i}\right)=u_{i}\left(q_{j}\right)=u_{z} \text { for all } j
\end{aligned}
$$

The testable implication of these two conditions is that $Q_{i j} \geq 1$ for all $j$. To see why, suppose instead that $Q_{i k}<1$ for some region $k$ i.e., $p_{i} q_{k}<p_{i} q_{i}$. Then the bundle $q_{k}$ was affordable in region $i$ with the expenditure required for obtaining $q_{i}$. However, for consistency, $q_{i}$ is the utility-maximizing bundle for someone at the poverty line in region $i$; furthermore, given convex indifference curves, $q_{i}$ is the unique such bundle. Then, $q_{i}$ must have been strictly preferred to $q_{j}\left(u_{i}\left(q_{i}\right)>u_{i}\left(q_{j}\right)\right)$, which contradicts welfare consistency.

Notice that our test is necessary for utility consistency, but it is not sufficient. It is possible to find that $Q_{i j} \geq 1$ and yet bundles $i$ and $j$ do not yield the same utility when judged by $i$ 's preferences. Figure 3 illustrates this point. Four bundles of two goods are identified. Point B represents the poverty bundle for region B, with the indifference curve indicated, while A, C and $\mathrm{D}$ are the bundles for three other regions. When assessed by region B's preferences, we can reject consistency between $\mathrm{A}$ and $\mathrm{B}$; bundle $\mathrm{A}$ must be on a lower indifference curve than $\mathrm{B}$. However, we cannot reject for $\mathrm{C}$ and $\mathrm{D}$ happen to be welfare consistent with $\mathrm{B}$; as drawn, $\mathrm{C}$ and $\mathrm{B}$ are consistent, but we do not of course know the actual indifference curves in practice.

Also note that it is possible to find that $Q_{i j} \geq 1$ but $Q_{j i}<1$. In other words, we may be unable to reject utility consistency between the bundles for regions $i$ and $j$ when assessed using 
$i$ 's price relatives, yet we can reject it when using $j$ 's. If we find that $Q_{i j} \geq 1$ but $Q_{j i} \geq 1$ we will say that the bundles $i$ and $j$ are mutually utility consistent.

By repeating our test for successive rows of the $\boldsymbol{Q}$ matrix we can test consistency across the complete set of underlying (unknown) preferences. So the key testable implication of consistent poverty lines across the full set of preferences is that none of the elements of the $\boldsymbol{Q}$ matrix should be below unity.

Our test allows the possibility that preferences over commodities differ across the poverty profile, but it does so in a special way, namely that one compares the poverty bundles of different regions at a common utility function. The rejection of utility consistency could reflect heterogeneity in preferences.

Notice also that this is a joint test of the two consistency requirements in (10.1) and (10.2), and if one fails to hold then the test loses all power to detect whether the other holds. For example, suppose that the bundle of goods on which a poverty line is based would not be chosen by someone at the poverty line income given the prevailing prices. Then it can still satisfy (10.2) even though our quantity index is less than unity.

If consistency is rejected, it is of interest to ask whether there is a set of scalar adjustments to the original poverty lines that will assure they pass our consistency tests. There is nothing to guarantee that such a set of scalar corrections exists; possibly the only way to pass the test is to re-design the original bundles. However, there is a straightforwardly testable necessary condition for the existence of a set of scalar corrections that will assure that our consistency test passes. To see what this entails, let $k_{i}$ denote the scalar adjustment made to all the elements of the vector $q_{i}$ and consider the case of $n=2$ so the adjusted $\boldsymbol{Q}$ matrix is given by: 


$$
\left[\begin{array}{cc}
1 & \frac{k_{2} p_{1} q_{2}}{k_{1} p_{1} q_{1}} \\
\frac{k_{1} p_{2} q_{1}}{k_{2} p_{2} q_{2}} & 1
\end{array}\right]
$$

If the scalar corrections $k_{1}$ and $k_{2}$ entail that our test is passed then it must be the case that:

$$
\frac{p_{1} q_{1}}{p_{1} q_{2}} \leq \frac{k_{2}}{k_{1}} \leq \frac{p_{2} q_{1}}{p_{2} q_{2}}
$$

This in turn implies that $Q_{12} Q_{21}=\left(r_{2} q_{1}\right)\left(r_{1} q_{2}\right) \leq 1$. In other words, a necessary condition for the existence of a set of scalar corrections to the bundles to assure that our consistency test passes is that the product of the off-diagonal elements of the $\boldsymbol{Q}$ matrix cannot exceed unity. Extending this idea to the case of $n$ regions, the necessary (but not sufficient) condition becomes that $Q_{i j} Q_{j i} \leq 1$ i.e., the product of the $(i, j)$ and $(j, i)$ mirror-opposite elements cannot exceed unity.

\section{Case study for Russia}

Russia's official poverty lines were established under guidelines developed by the Ministry of Labor and Social Development (MLSD, 2000). The poverty line is defined as the cost of specific baskets of goods and services that are deemed necessary for an individual to maintain health and a minimum activity levels, both personal and social, taking account of the geographic setting (notably climate).

The food baskets are defined based on nutritional requirements for calories, proteins, fats, and carbohydrates for five groups of individuals: Children aged 0 to 6 , children 7 to 15 , adult males 16 to 59, adult females 16 to 54, and retired people (males 60 years of age and older and females 55 and older). The baskets vary across the 16 geographical zones of Russia, as shown in Figure 4(a), to account for calorific differences by climatic zones and for regional differences in 
food consumption patterns. The caloric requirements for adult males, for example, range from $3030 \mathrm{kcal}$ per day for the northern regions of Russia (food zones 1,2, and 3) to $2638 \mathrm{kcal}$ per day for the warmer zones. Norms for the consumption of proteins and carbohydrates can also vary substantially across zones. The final food poverty bundles comprise 34 items, which differ between zones. For example, northern zones include deer meat while the southern zones include larger shares of (relatively cheaper) fruits and vegetables. Food bundles for the zones with a predominantly Muslim population do not include pork.

Three zones for non-food goods and three zones for services/utility baskets (Figures $4 \mathrm{~b}$ and $4 \mathrm{c}$ respectively) are defined according to climatic conditions in Russia. The basket for nonfood goods provides detailed quantities to be consumed by six groups of individuals. These groups are similar to the groups used in the construction of the food basket, except that separate baskets for non-food goods are defined for elderly men and women. The service basket consists of consumption norms for seven main utilities. While the food and non-food baskets are defined at the individual level, the service baskets are defined on a per capita basis.

The non-food bundles consist of a number of personal items and some consumer durables. The non-food goods include specific items of clothing, footwear, pens and notebooks. Goods for the household's collective use include furniture (table, chair, chest of drawers, mirror, etc.), appliances (TV, refrigerator, clocks,...), kitchen items (plates, pots and pans, silverware), as well as towels, sheets, blankets, and pillows. Every item in the non-food bundle has an approximate usage time that varies for different age-gender groups. For example, adult males aged 18 to 59 are supposed to use one coat for seven years, while the norm for male pensioners is 10 years. A blanket has a life-time of 20 years. Every prime age woman is entitled to five underwear with amortization period of 2.4 years and two bras every three years. 
The services bundle includes allowances for housing, heating, electricity, hot and cold water, gas and transportation. ${ }^{9}$ The norms for heating and electricity vary by zones. In the cold climate zones the per person heat consumption is equal to 8.0 Gcal (Giga calories) per year while in the warmer zones it is only 5.4 Gcal per year per person.

Price information on the items in the poverty baskets is collected quarterly by the Russian Central Statistical Agency ("GosComStat") in 203 cities and towns of Russia for 196 food and non-food items and services. ${ }^{10}$ The poverty lines for every geographical zone are calculated by multiplying the quantities of the items in the baskets by the corresponding prices in an appropriate city or town within the zone.

In order to construct a poverty line for a particular region the cost of the food basket corresponding to this region should be added to the regional costs of the non-food goods and services. While the North-Eastern Zone I for non-food goods and Zone I for services overlap almost completely, Zones II and III cover different regions in central and southern Russia. In addition, the boundaries of the non-food goods and services zones in several cases split the food zones on two or more smaller zones. As a result, we can define 23 geographical zones that correspond to the combinations of food, non-food goods and services zones (as identified in Figure 5, which we return to below). One hundred and thirty eight distinct baskets are specified as a combination of these geographical zones and the six age-gender groups.

The actual compositions of goods and services that enter the regional baskets are determined by local governments. An inter-ministry expert committee reviews the draft consumer baskets submitted by the local governments and provides recommendations to the

\footnotetext{
$9 \quad$ There is no allowance for health or education since by law (at least) these are free in Russia. 10 GosKomStat does not collect prices in the rural areas of Russia and poverty lines are thus based on urban prices. This could result in overestimation of the poverty rates in rural areas.
} 
Federal Government, which makes the final decision on the composition of the regional baskets. ${ }^{11}$ The expert committee evaluates the nutritional composition of every regional basket as well as the composition of the non-food components (VTsUZH, 2002).

Table 1 shows the poverty lines in Russia in September 2002 prices (rubbles per month). Low-numbered zones in the table roughly correspond to the northern regions while high-number zones correspond to the south. The values of poverty lines tend to decline from north to south. For example, the poverty line for an adult male aged 16 to 59 is 2534 rubbles per month for Zone 2 compared to only 1307 rubbles per month in Zone 20. Similar tendencies can be observed for other age-gender categories.

Comparing poverty lines among different age-gender groups demonstrates that, as one would expect according to nutritional requirements, poverty lines for adult males are higher than the poverty lines for adult females and for the elderly. However, in many cases, poverty lines for children are higher than poverty lines for other categories. The reason is that in Russia, the nutritional requirements for children are based not only on the norms for calories, proteins, fats, and carbohydrates, but also include minimum amounts of micronutrients and vitamins. To satisfy these requirements for micronutrients the food basket for children includes more expensive items that result in higher poverty lines (Baturin 2003).

The household poverty line is determined by summing up the individual poverty lines of the household members. For our analysis we use the poverty lines for a typical household that consists of two parents (a male aged 18 to 59 and a female aged 18 to 54) and two children (one child 0 to 6 years old and one child 7 to 15 years old). We call this the "reference household."

11 The results of the latest 2001 review of the regional baskets indicate that out of 89 submitted proposals, 67 drafts attracted no criticism, while the remaining 22 drafts deviated in one way or another from the methodological recommendation. 
Before we turn to our tests, it is worth reflecting on why we might expect inconsistencies in these poverty lines. Partial capability consistency seems reasonably well assured, given that the lines are anchored to food-energy requirements specific to each geographic and demographic groups. Consistency in terms of other capabilities is less clear. The long list of essential nonfood goods and services clearly reflect perceptions by the relevant committees of what is needed to maintain minimal activity levels in the specific setting, recognizing that this is more than a matter of adequate nutrition, but requires expenditures on clothing, housing, heating and transportation. Arguably there is a sense in which consistency with a reasonably broad set of capabilities for active participation in Russian society is built into this method of setting poverty lines.

However, no obvious attempts are made to assure utility consistency (in any explicit sense) of the poverty lines across regions. There can be random differences. But there are also likely to be systematic differences arising from two sources. Firstly, perceptions of what constitutes "poverty" will undoubtedly differ, with richer provinces tending to have higher real poverty lines (just as is found across countries; see Ravallion, 1994). (Clearly, this could generate capability inconsistencies too.) Secondly, and probably working against the first factor, resource poor local governments in Russia may perceive an incentive to inflate their poverty lines to attract extra resources from the center. According to the Law on Social Protection any family or single person whose average per-capita income is below the regional poverty line is entitled to receive government social assistance. The Federal Government allocates funds for social protection based on the number of poor in the region. Therefore, the local governments have an incentive to inflate their baskets to secure a larger share of government transfers to the 
region. Furthermore, this incentive may well be stronger for poorer local government areas. On balance, we cannot predict which direction the bias might go.

\section{Revealed preference tests for Russia's poverty lines}

Table 2 gives the matrix of the costs of the poverty baskets for the reference household across the 23 zones. The number in row $i$, column $j$ gives the cost in zone $i$ of the zone $j$ poverty basket. Thus, the actual poverty lines are on the main diagonal.

The corresponding $\boldsymbol{Q}$ matrix of Laspeyres quantity indices is given in Table 3 . Comparing columns of the matrix, it is evident that the two most generous poverty bundles are those for zones 2 and 3, which make up Siberia. One of these dominates all other bundles, though 2 and 3 cannot be ranked unambiguously; for some price vectors, the zone 2 bundle dominates while for others it is zone 3 . However, there can be no doubt which is the least generous bundle judged by the quantity index; the bundle for zone 20 is unconditionally lower than that for all other bundles, i.e., $Q_{i 20}<Q_{i j}$ for all $j \neq 20$. Zone 20 is the small region of Kalmukia in the southwest.

Figure 5 gives the results of our revealed preference test based on the quantity matrix in Table 3. The elements of $\boldsymbol{Q}$ that are less than 1 (i.e., the test is not passing) are shaded. Overall, the test is passed for only 281 out of 529 elements of $\boldsymbol{Q}$ matrix. ${ }^{12}$ Strikingly, of the 253 distinct pairs of bundles, mutual utility consistency is rejected for all except six pairs, namely the pairs $(10,17),(10,23),(11,9),(11,15),(23,13)$ and $(23,17)$. Looking at the first row, we find that utility consistency at common preferences is rejected for all but two of the $(i, j)$ combinations.

12 Consistency tests for the individual $\boldsymbol{Q}$ matrixes show different numbers of passing elements (Figure 1 in Appendix). The adult male matrix has 250 passes, while the matrices for adult females, children 0 to 7 and children 7 to 15 have 251,247 and 248 respectively. 
Consistency is rejected for all regions when judged by region 3's preferences. Rejections tend to become less common as one moves down the table. The test comes very close in region 16 , with only one narrow $\left(Q_{16,20}=0.984\right)$ rejection.

Zone 20 stands out as unusual in three respects. Firstly, as we have noted, it is the bundle with the lowest quantity index for all prices. Secondly, it is the only bundle that passes out test; judged by zone 20's preferences, we cannot reject consistency across all the bundles. Thirdly, the bundle for zone 20 accounts for more rejections than any other zone. Indeed, there is no zone for which consistency with zone 20 passes. Clearly these three observations are related. The low value of the zone 20 bundle makes it more likely to be utility consistent, and more likely to differ from the bundles elsewhere.

One might argue that some relaxation of our test criterion is warranted to account for errors. There is no way of calculating standard errors for the $\boldsymbol{Q}$ matrix since there is no explicit sampling or parameter estimation involved. The best we can do is simply to test sensitivity to relaxing the test criterion. Figure 6 shows how the share of poverty lines passing the test varies with the test criterion. For example, if we relax the test conditions to allow values of $Q_{i j}>0.950$ to pass then the number of elements that satisfy the consistency test would increase by almost $20 \%$ to 350 cells. It is clear that even under far less stringent conditions, a large share of the Russia regional poverty lines do not pass our test.

Is it possible to find scalar transformations of the poverty bundles that would satisfy our revealed preference test? Recall that a necessary condition for the existence of such a vector is that all the products of mirror-opposite elements of $\boldsymbol{Q}$ matrix are less than or equal to one. Analyzing the numbers shown in Table 3 we find that the product of opposite elements does not exceed unity for only 57 out of 144 pairs in the $\boldsymbol{Q}$ matrix. This property of the $\boldsymbol{Q}$ matrix rejects 
the possibility of finding a set of simple scalar corrections to the original bundles that will assure that our consistency test passes. The internal composition of the bundles would need to change.

Why are our revealed preference criteria rejected so strongly? As we noted in the last section, the decentralized process generating Russia’s regional poverty bundles may well yield utility inconsistencies. However, we cannot rule out geographic heterogeneity in preferences as an alternative explanation. Figure 7 maps the mean quantity indices $\left(\bar{Q}_{j}\right)$. There is a marked north-south difference, which is clearly correlated (negatively) with temperature; Figure 8 maps mean temperatures. ${ }^{13}$ The cooler the climate, the more generous the bundle as measured by the mean quality index. This suggests that the differences in the consumption bundles may well reflect differences in the commodities needed to reach the same utility level in different climates.

However, climate differences do not account for the violations of our revealed preference tests. By superimposing the temperature map (Figure 8) on the zones for which distinct poverty lines are identified (Figure 7) we can identify four distinct clusters of zones within a close range of temperatures, as identified in Table 4, which also give results of our revealed preference tests within each of these clusters. Again, rejections are indicated for about half the cases. ${ }^{14}$ Mutual utility consistency is rejected for every pair within each temperature band.

\section{Conclusions}

We have argued that possibly the most common method of setting poverty lines in practice — whereby the poverty line is the income at which pre-determined food-energy

13 Given that the temperature map is at a much finer level, calculating a correlation coefficient would require considerable aggregation. From eye-balling the figures, the extent of the correlation is clearly high, however.

14 It is also readily verified from Table 4 that our necessary conditions for existence of a set of scalar corrections that will assure that our test passes are satisfied for clusters 1 and 4, while these conditions are rejected (though narrowly) for clusters 2 and 3. 
requirements are met in expectation in each subgroup — is unlikely to be utility consistent. Nor is this method likely to be consistent in terms of a broader set of functionings.

The poverty lines obtained by the main alternative method found in practice — the "costof-basic needs" method - have the potential to be utility consistent, and consistent for a broader set of normative functionings than reaching adequate nutritional status. Whether they are in practice is a moot point. The specification of "basic consumption needs" is typically motivated by ideas of certain minimum functionings, notably (but not only) the ability to secure nutritional requirements. Their utility consistency is less obvious. In cases in which a complete set of basic consumption needs has been specified, we have shown that utility consistency for given preferences implies a straightforward empirical test, drawing on the theory of revealed preference.

As a case study, we have applied revealed preference tests to the official poverty lines for Russia. We find that we can generally reject utility consistency. Indeed, for only one region's preferences do we find that our test passes. For all other region's preferences, we reject consistency across at least one other regional bundle. Nor does there exist a set of scalar corrections that would assure our test passes. Satisfying revealed preference criteria would require internal corrections to the original poverty bundles, changing their composition.

These rejections of our revealed preference tests may stem in part from underlying heterogeneity in preferences. The correlation we find across areas between the value of the Russian poverty bundles and mean temperature is suggestive of climatic differences in preferences, such that the same consumption does not yield the same utility in markedly different climates. Indeed, finding more generous bundles in colder climates is to be expected if the poverty lines are in fact utility consistent. 
However, we still find numerous rejections of utility consistency when we control for climatic differences, by repeating our test for clusters of geographic areas within the same temperature band. The evidence of utility inconsistencies that we find in Russia's official poverty lines could well stem from the decentralized administrative process generating the poverty bundles. This may be less of a problem in settings in which the task of setting the normative bundles is more centralized. 


\section{References}

Baturin, A., (2003) "Development of the Food Component of the Poverty Line in Russia." Mimeo, World Bank, Washington, D.C.

Blackorby, C., and D. Donaldson (1987), "Welfare Ratios and Distributionally Sensitive CostBenefit Analysis", Journal of Public Economics 34: 265-290.

Citro, Constance F., and Michael, Robert T., (1995), Measuring Poverty: A New Approach. Washington DC: National Academy Press.

Dandekar, V.M., and N. Rath (1971), Poverty in India. Pune: Indian School of Political Economy.

Deaton, Angus and John Muellbauer (1980), Economics and Consumer Behavior, Cambridge: Cambridge University Press.

Greer, J., and Erik Thorbecke (1986), “A Methodology for Measuring Food Poverty Applied to Kenya," Journal of Development Economics 24: 59-74.

Kapteyn, Arie, Peter Kooreman, and Rob Willemse (1988), "Some Methodological Issues in the Implementation of Subjective Poverty Definitions," Journal of Human Resources 23: $222-242$.

Ministry of Labor and Social Development (MLSD) (2000) "Prozhitochnui Minimum V Rosiiskoi Federacii (The Subsistence Minimum in Russian Federation).” MLSD, Moscow, Russia.

Orshansky, Molly (1963), "Children of the Poor," Social Security Bulletin 26: 3-29.

Osmani, Siddiqur (1982) Economic Inequality and Group Welfare Oxford: Oxford University Press.

Palmer-Jones, Richard and Kunal Sen, (2001) “On India's Poverty Puzzles and Statistics of Poverty," Economic and Political Weekly, January 20, pp. 211-217.

Paul, Satya, (1989), “A Model of Constructing the Poverty Line,” Journal of Development Economics 30: 129-144.

Pradhan, Menno and Martin Ravallion, (2000), "Measuring Poverty Using Qualitative Perceptions of Consumption Adequacy", Review of Economics and Statistics, 82(3): 462-471.

Ravallion, Martin (1994), Poverty Comparisons, Chur, Switzerland: Harwood Academic Press. 

, (1998), Poverty Lines in Theory and Practice, LSMS Paper 133, Washington DC, World Bank.

Ravallion, Martin and Benu Bidani (1994), "How Robust is a Poverty Profile?" World Bank Economic Review, 8 (1): 75-102.

Ravallion, Martin and Binayak Sen (1996) "When Method Matters: Monitoring Poverty in Bangladesh," Economic Development and Cultural Change, 44: 761-792.

Samuelson, Paul (1938), “A Note on the Pure Theory of Consumer Behaviour” Economica 5: $61-71$.

Sen, Amartya (1979), “The Welfare Basis of Real Income Comparisons: A Survey,” Journal of Economic Literature 17: 1-45. (1985), Commodities and Capabilities, Amsterdam: North-Holland. (1992), Inequality Rexamined, Oxford: Oxford University Press.

VTsUZH (2002), "Living Standards of the Population of the Russian Federation. Legal Basis for Minimal Monetary Incomes.” Part 1, Moscow, pages 220-225.

Wodon, Quentin (1997), "Food Energy Intake and Cost of Basic Needs: Measuring Poverty in Bangladesh,” Journal of Development Studies 34: 66-101.

World Health Organization (WHO) (1985), Energy and Protein Requirements, WHO, Technical Report Series 724, Geneva. 
Table 1: Official poverty lines for Russia by geographical zones and age-gender groups

\begin{tabular}{lcccccc}
\hline & Adult & Adult & Elderly & Elderly & Children & Children \\
Zone & Male & Female & Male & Female & $0-6$ & $7-15$ \\
\hline 1 & 2124 & 1833 & 1314 & 1387 & 2129 & 2062 \\
2 & 2534 & 1558 & 1635 & 1380 & 2018 & 2991 \\
3 & 2170 & 1934 & 1500 & 1466 & 2113 & 2349 \\
4 & 1942 & 1686 & 1324 & 1264 & 1854 & 2066 \\
5 & 1466 & 1265 & 1034 & 955 & 1510 & 1649 \\
6 & 1582 & 1370 & 1100 & 1028 & 1583 & 1740 \\
7 & 1719 & 1508 & 1204 & 1143 & 1705 & 1858 \\
8 & 1483 & 1297 & 991 & 954 & 1501 & 1656 \\
9 & 1552 & 1374 & 1084 & 1031 & 1639 & 1785 \\
10 & 1434 & 1227 & 983 & 909 & 1515 & 1598 \\
11 & 1571 & 1519 & 1150 & 1041 & 1694 & 1774 \\
12 & 1534 & 1404 & 1042 & 1023 & 1560 & 1720 \\
13 & 1383 & 1181 & 961 & 896 & 1475 & 1588 \\
14 & 1867 & 1643 & 1293 & 1235 & 1846 & 2033 \\
15 & 1594 & 1397 & 1119 & 1069 & 1671 & 1789 \\
16 & 1381 & 1180 & 957 & 881 & 1454 & 1573 \\
17 & 1409 & 1218 & 1007 & 940 & 1506 & 1556 \\
18 & 1663 & 1486 & 1159 & 1122 & 1696 & 1867 \\
19 & 1472 & 1265 & 1038 & 967 & 1517 & 1657 \\
20 & 1307 & 1151 & 927 & 879 & 1447 & 1560 \\
21 & 1451 & 1241 & 1031 & 953 & 1579 & 1656 \\
22 & 1415 & 1232 & 1007 & 925 & 1470 & 1596 \\
23 & 1361 & 1200 & 1001 & 944 & 1457 & 1554 \\
\hline \hline
\end{tabular}

Note: Poverty line is calculated in 2002 rubles, per month 
Table 2: Poverty lines by zones for the reference household of two parents two children. September 2002 rubbles per month.

\begin{tabular}{|c|c|c|c|c|c|c|c|c|c|c|c|c|c|c|c|c|c|c|c|c|c|c|c|}
\hline & \multicolumn{23}{|c|}{ aske } \\
\hline & 1 & 2 & 3 & 4 & 5 & 6 & 7 & 0 & 9 & 10 & 11 & 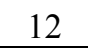 & 3 & 1 & 1 & 16 & & 18 & 19 & 0 & 1 & 2 & 23 \\
\hline 1 & 148 & 222 & 152 & 003 & & 720 & 252 & & 911 & & & & & & & & & & & & & & \\
\hline 2 & & & & & & & & & & & & & & & & & & & & & r & 38 & \\
\hline 3 & 686 & 571 & 566 & & & & & & & & & & & & & & & & & & 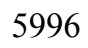 & 98 & \\
\hline 4 & 7701 & 706 & 656 & 48 & 99 & 5 & 58 & 84 & 40 & 90 & 61 & 81 & 690 & 362 & & 670 & 727 & & 08 & & 28 & 67 & 194 \\
\hline 5 & 7607 & 655 & 657 & 525 & 890 & 277 & 94 & 15 & 48 & 34 & 197 & 75 & 2 & 326 & & 1 & & & & & & & 794 \\
\hline 6 & 7603 & & & 522 & & 4 & & & & & & & & & & & & & & & & & 792 \\
\hline 7 & & & & & & & & & & & & & & & & & & & & & & 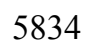 & 90 \\
\hline 8 & & & & & & & & & & & & & & & & & & & & & & & \\
\hline 9 & & & & & & & & & & & & & & & & & & & & & & & \\
\hline 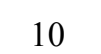 & & & & & & & & & & 4 & & & & & & & & & & & & & 774 \\
\hline 1 & 12 & 731 & 723 & 7678 & 6065 & 6 & 7 & & & 9 & 7 & & & 3 & & & & & & & & & 783 \\
\hline 10 & 90 & 689 & 680 & 7651 & 6057 & 6413 & 68 & 6100 & 56 & 5776 & 0 & 9 & 2 & 301 & & & & & & & & & 761 \\
\hline & 572 & 470 & 491 & 7500 & 5871 & 6264 & 6667 & 5947 & 63 & 642 & 4 & 27 & 627 & 201 & 50 & 0 & & & & & & & 638 \\
\hline 14 & 23 & 749 & 718 & 75 & 81 & & & 142 & & 3 & 9 & & 3 & 389 & 1 & 25 & & & & & & & 790 \\
\hline 15 & & & & 7481 & & & & & 2 & 5 & & 2 & 9 & & & & & & & & & & 5755 \\
\hline 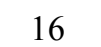 & & & & & & & & & & & & & & & & & & & & & & & 5713 \\
\hline & & & & & & & & & & & & & & & & & & & & & & & 5740 \\
\hline & & & & & & & & & & & & & & & & & & & & & & & 5738 \\
\hline & & & & & & & & & & & & & & & & & & & & & & & 5681 \\
\hline 2 & & & & & & & & & & & & & & & & & & & & & & & 5657 \\
\hline 21 & & & & & & & 6679 & & & & & 0142 & & & & & & & & & & & 5655 \\
\hline 22 & & 8439 & 8437 & 7471 & 5852 & 6228 & 6629 & 5929 & 6322 & 5633 & 6345 & 6134 & 5608 & 7167 & 6412 & 5524 & 5609 & & & & & 5713 & 5640 \\
\hline 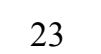 & 7437 & 8359 & 8360 & 7411 & 5800 & 6190 & 6585 & 5862 & 6301 & 5593 & 6297 & 6087 & 5571 & 7145 & 6366 & 5492 & 5576 & 6585 & 5813 & 5426 & 5846 & 5665 & 5571 \\
\hline
\end{tabular}




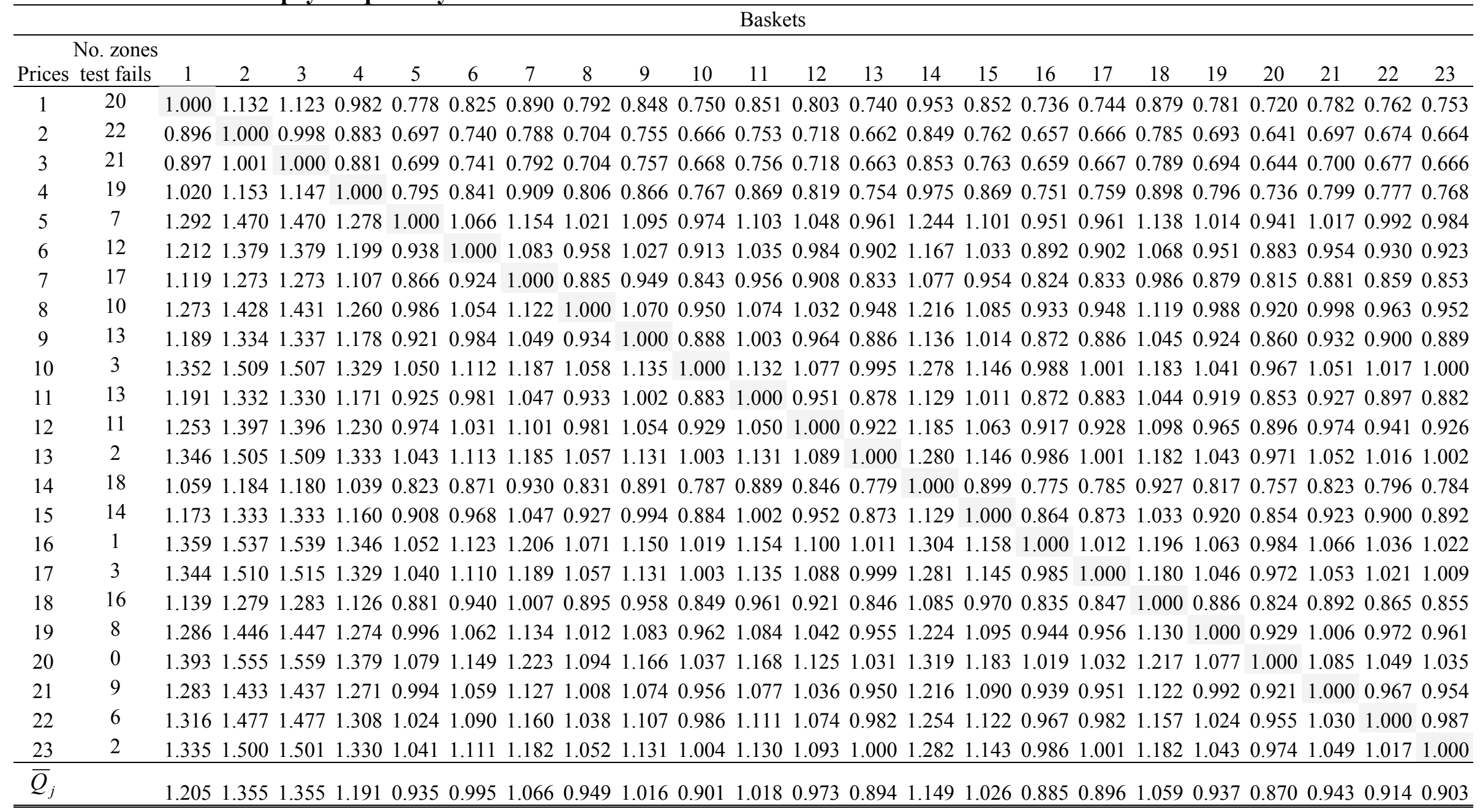


Table 4: Revealed preference tests for clusters of zone within common temperature bands Cluster 1: 8-10 $0^{\circ}$ Celsius zone

\begin{tabular}{c|cc}
\hline & \multicolumn{2}{|c}{ Zones } \\
\hline & 20 & 22 \\
\hline 20 & 1.000 & 1.049 \\
22 & 0.955 & 1.000 \\
\hline
\end{tabular}

Cluster 2: 2-4 $4^{0}$ Celsius zone

\begin{tabular}{c|cccc}
\hline & \multicolumn{3}{|c}{ Zones } \\
\hline & 5 & 15 & 16 & 18 \\
\hline 5 & 1.000 & 1.101 & 0.951 & 1.138 \\
15 & 0.908 & 1.000 & 0.864 & 1.033 \\
16 & 1.052 & 1.158 & 1.000 & 1.196 \\
18 & 0.881 & 0.970 & 0.835 & 1.000 \\
\hline
\end{tabular}

Cluster 3: 0-2 ${ }^{0}$ Celsius zone

\begin{tabular}{c|cccc}
\hline & \multicolumn{4}{|c}{ Zones } \\
\hline & 7 & 8 & 9 & 13 \\
\hline 7 & 1.000 & 0.885 & 0.949 & 0.833 \\
8 & 1.122 & 1.000 & 1.070 & 0.948 \\
9 & 1.049 & 0.934 & 1.000 & 0.886 \\
13 & 1.185 & 1.057 & 1.131 & 1.000 \\
\hline
\end{tabular}

Cluster 4: $-4--2^{0}$ Celsius zone

\begin{tabular}{c|ccc}
\hline & \multicolumn{3}{c}{ Zones } \\
\hline & 10 & 11 & 14 \\
\hline 10 & 1.000 & 1.132 & 1.278 \\
11 & 0.883 & 1.000 & 1.129 \\
14 & 0.787 & 0.889 & 1.000 \\
\hline
\end{tabular}




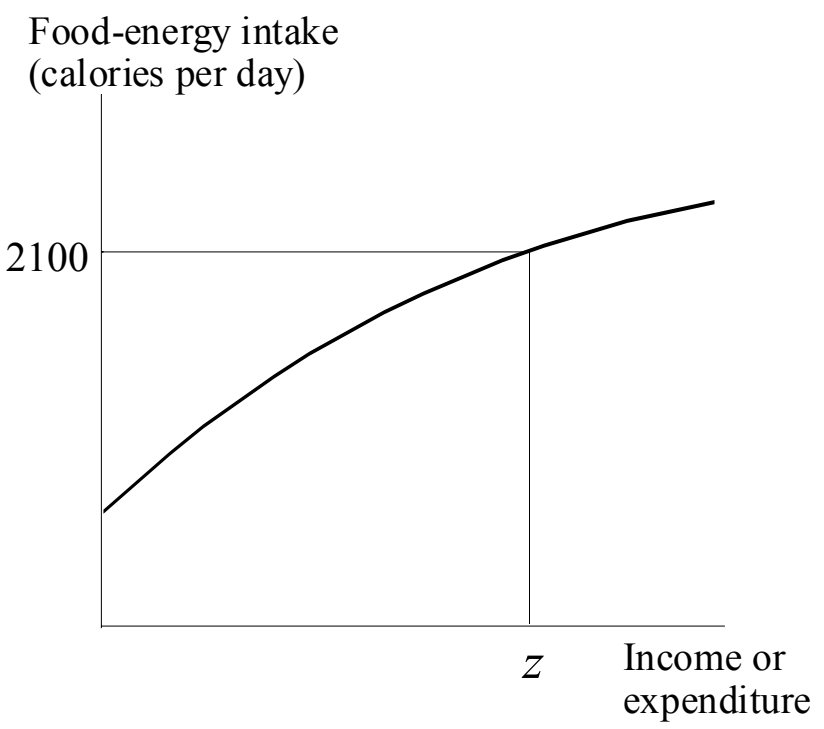

Figure 1: The food-energy intake method of setting poverty lines

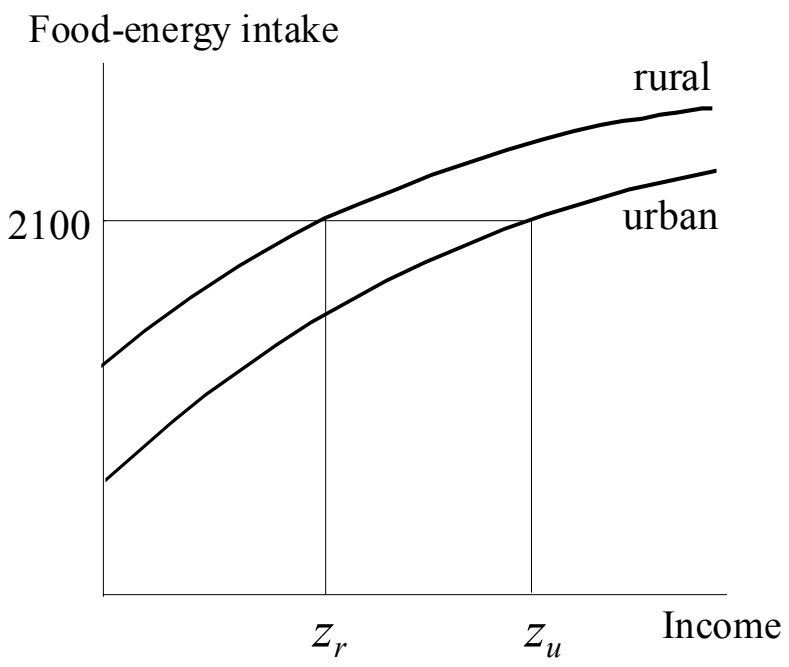

Figure 2: Multiple poverty lines with the FEI method 
Good 2

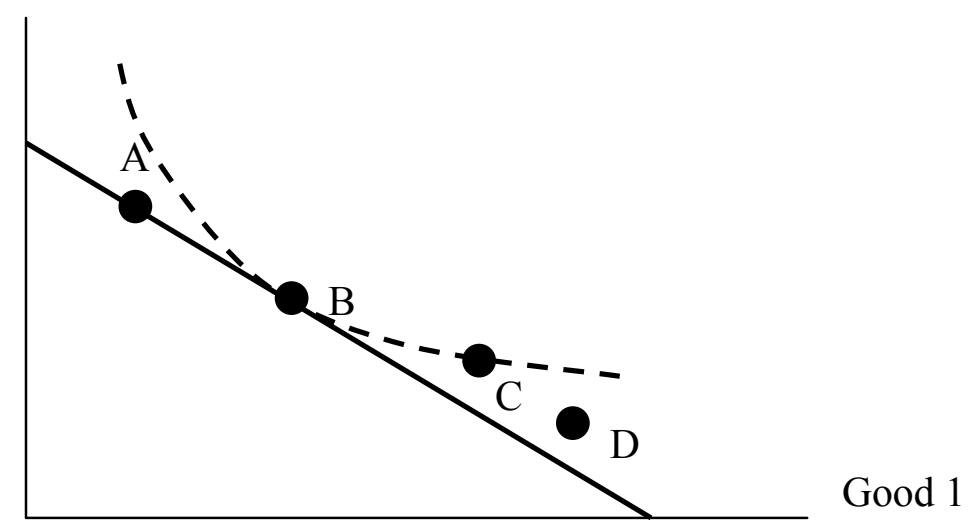

Figure 3: Consistency test for four bundles

Note: Consistency with bundle A is rejected for B but the test is inconclusive for C and D without knowing preferences. 


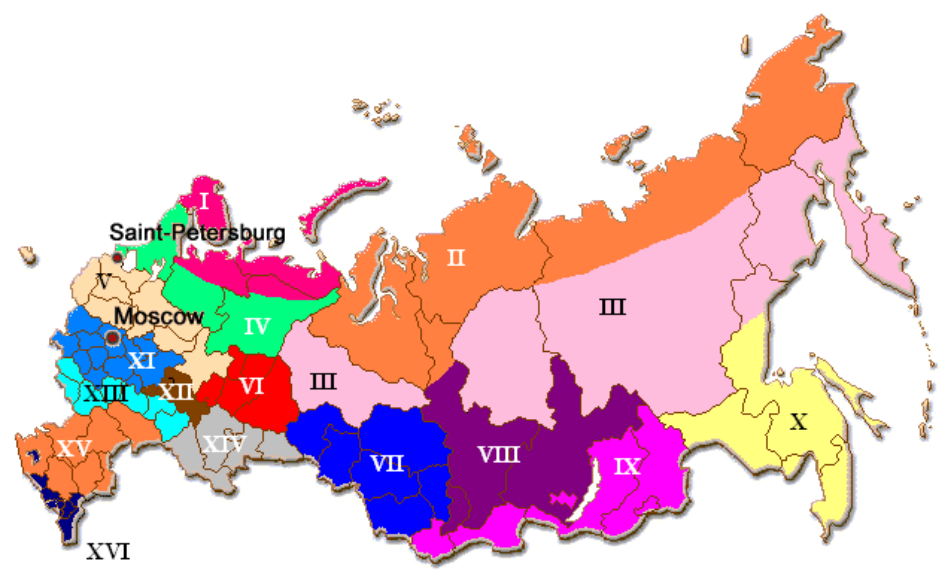

Figure 4(a): Zones for food baskets

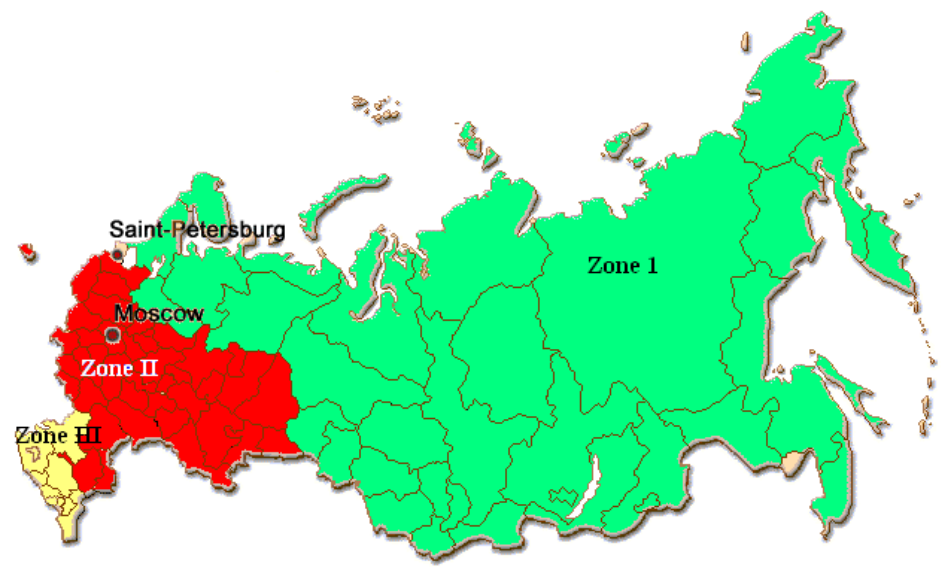

Figure 4(b): Zones for non-food goods

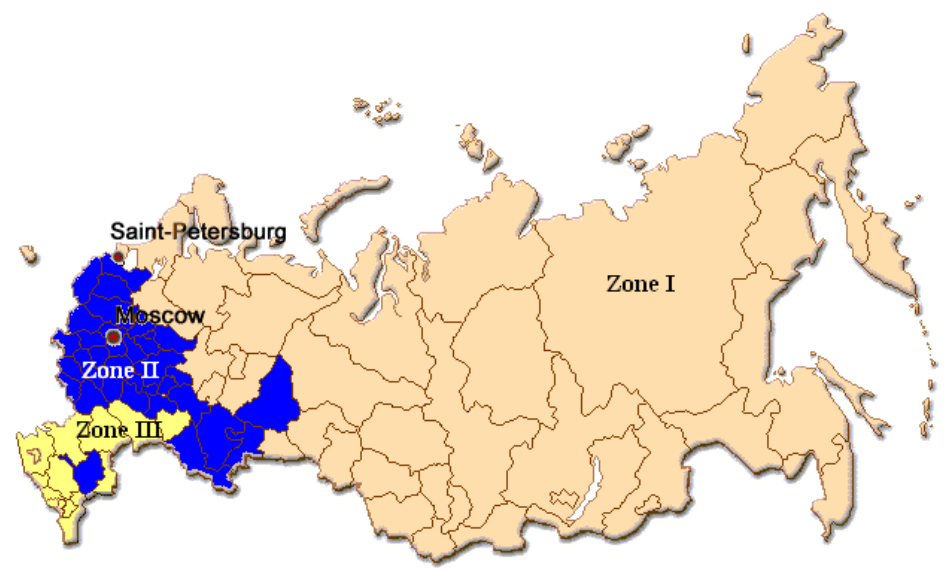

Figure 4(c): Zones for services 


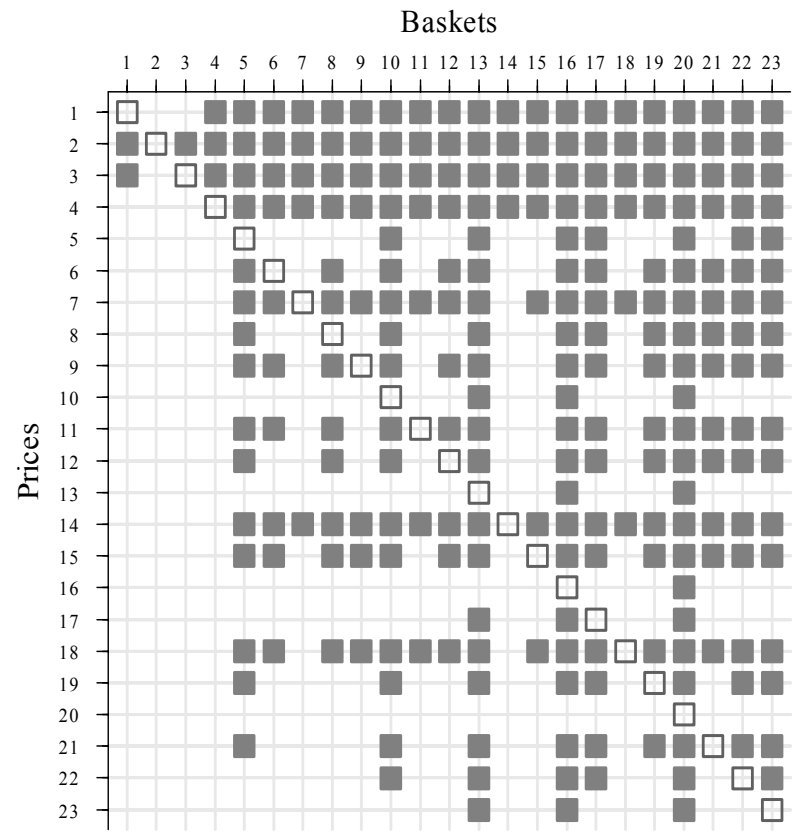

Figure 5: The results of the consistency test for Russian regional poverty lines

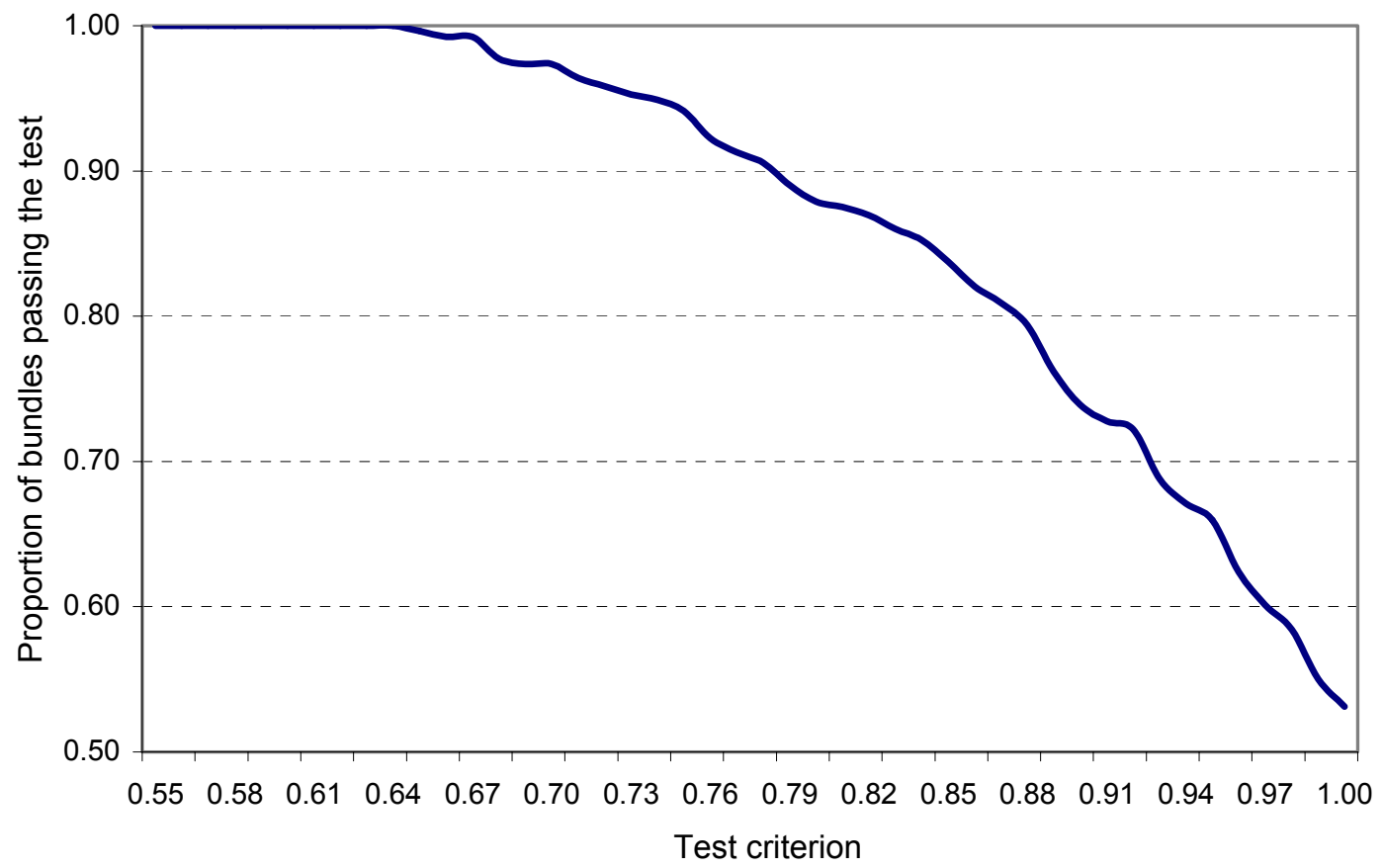

Figure 6: Proportion of bundles passing the poverty line consistency test for different test criteria. 


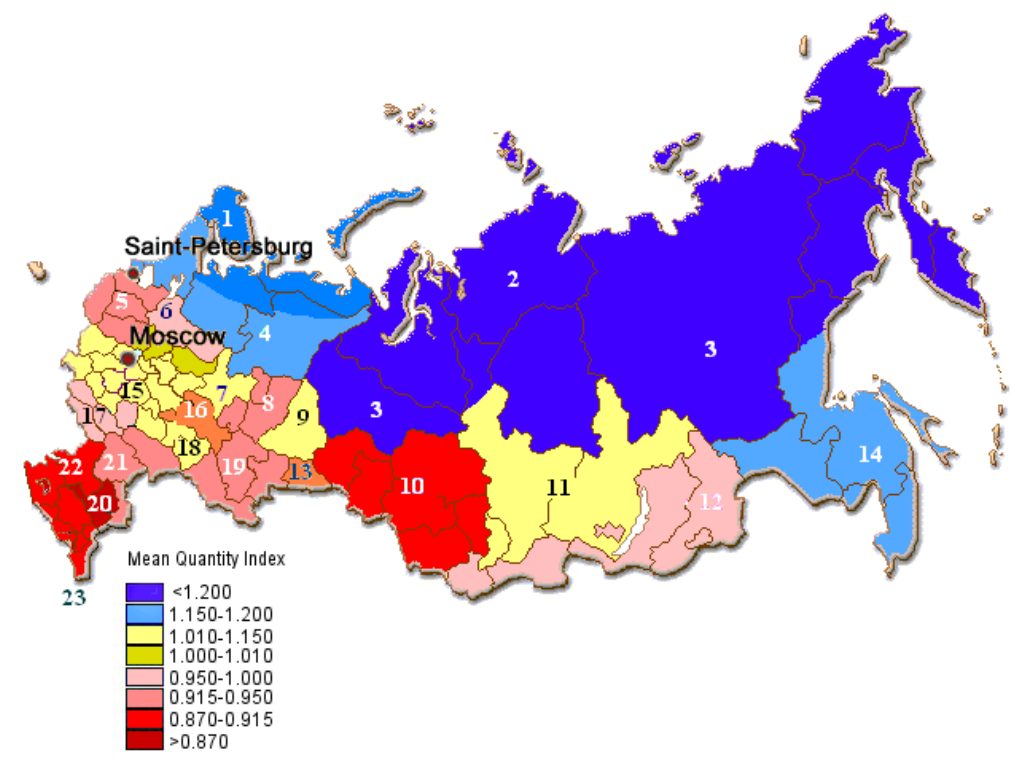

Figure 7: Mean quantity index by zone

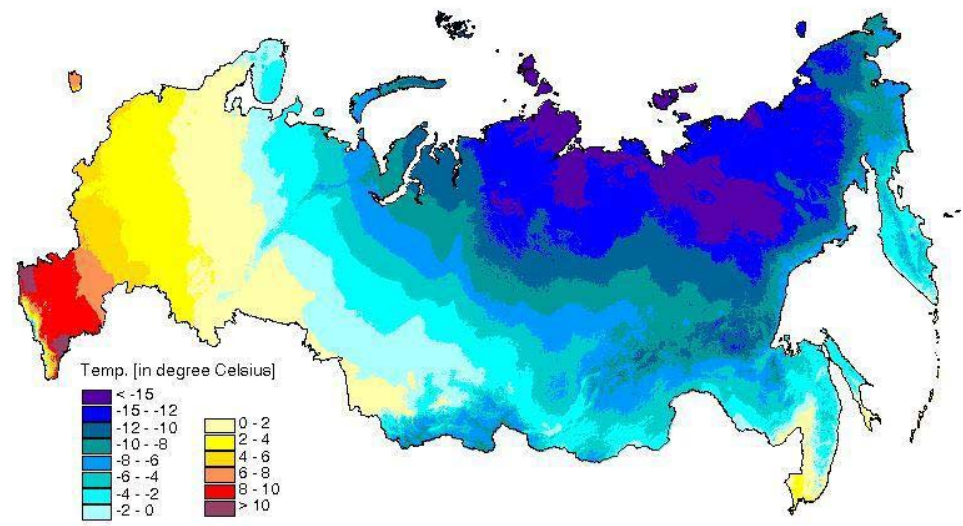

Figure 8: Mean annual temperature in Russia

Sources: Potsdam Institute for Climate Impact Research and Land Use Change Project IIASA -International Institute for Applied Systems Analysis, Austria (www.iiasa.ac.at/) 


\section{Appendix: Results of consistency test for individual matrixes of Laspeyres quantity indices}

Adult Males (279 passes)

\section{Baskets}

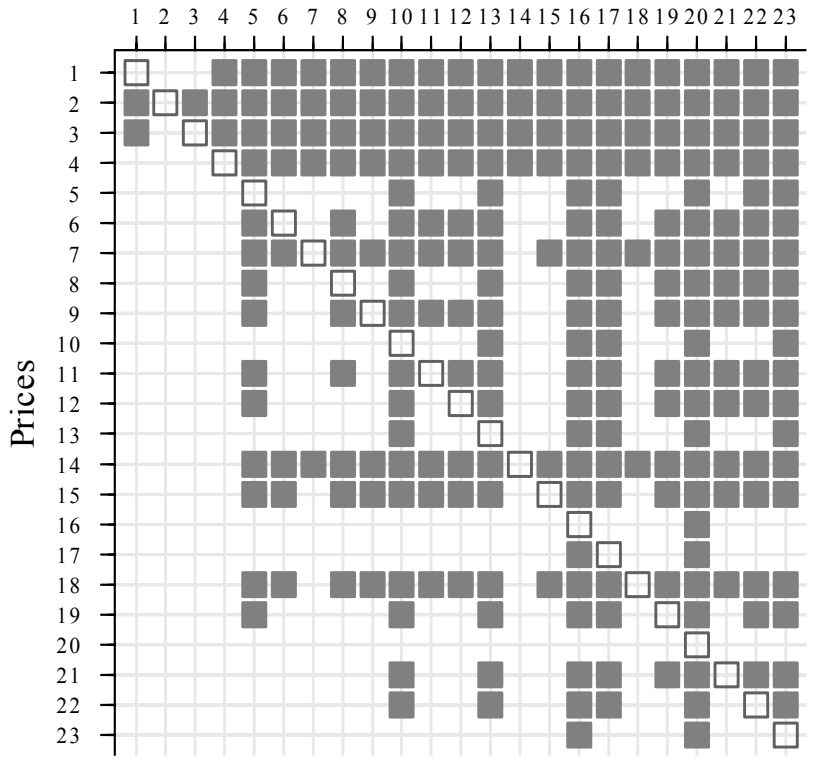

Adult Females (278 passes)

\section{Baskets}

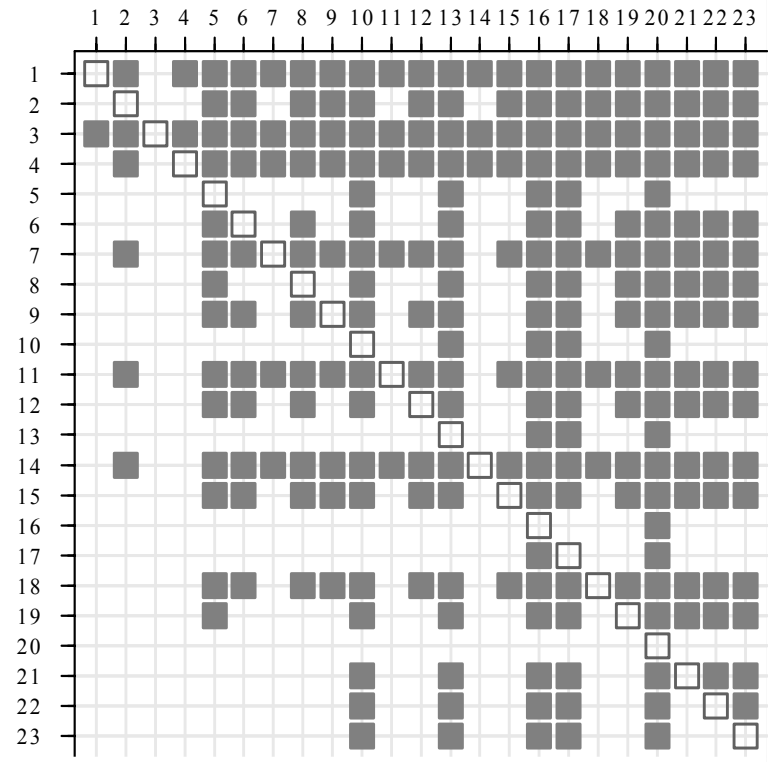

Children 7-15 (281 passes)
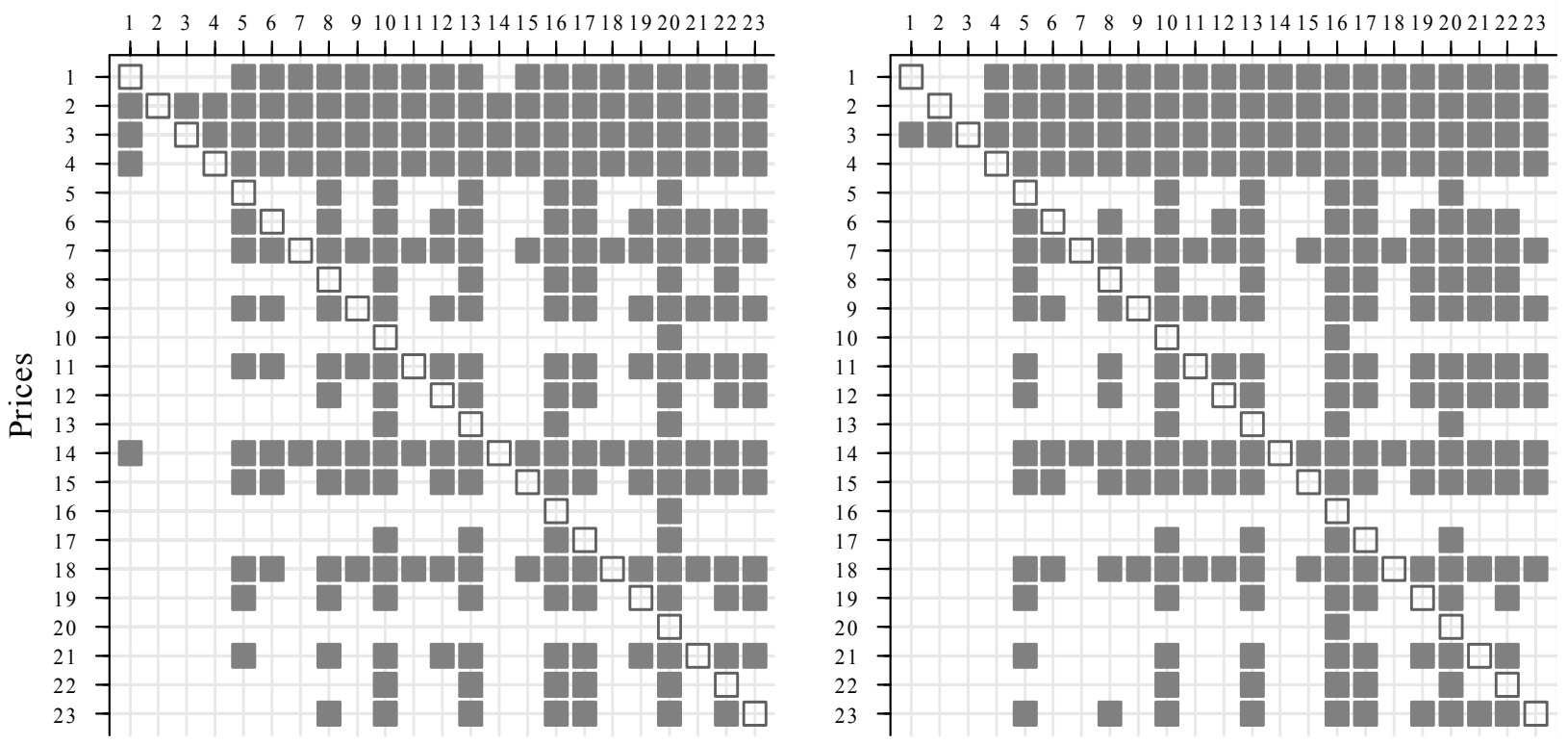